\title{
Tailings philosophies — to segregate or not to segregate
}

\author{
P.S. Wells Suncor Energy Inc., Canada
}

\begin{abstract}
Facilities in the oil sands of north-eastern Alberta have developed and operated several generations of technologies for the treatment of tailings resulting from bitumen extraction processes. These processes produce tailings streams that undergo segregation when discharged into water filled ponds. Coarse sand settles to the pond bottom as long beaches, while a percentage of the silts and clays remain suspended within the water column and are viewed as a major contributor to the oil sand challenges of water loss and storage volume increases. Traditional methods of dealing with these challenges have involved mainly recombining all the original solids (sands, silts and clays) into a non-segregating mixture. These methods assume that mixing the 'good' coarse material with the partially settled 'bad' suspended silts and clays can result in a well behaved, reclaimable deposit. This may not be the case, and it can be suggested that the pursuit of this goal may have created unrealistic objectives for tailings treatment, and served to slow development.

An alternative treatment philosophy is to identify the materials which are at the root of the existing tailings challenges and develop systems to isolate and treat those materials. Several technologies exist for this, and direct comparisons between these two philosophies involving the treatment material balances, process water balance, and material handling requirements can be made. Such comparisons have identified opportunities for improvements in the technology development focus by the various research and operational organisations and are beginning to produce alternative technologies that are more robust and effective.
\end{abstract}

\section{Introduction}

An integral part of the lifecycle of industry and science is the process of ongoing reviews and revisions of the direction taken to achieve objectives. This is healthy and necessary to ensure the advancement of knowledge and the continuation of productive technology development, and forms one of the key tenements of the scientific method.

Starting in early 2003, Suncor Energy embarked on a process review of its tailings operations. At the time, the base tailings and mining plan consisted of the following:

1. Construct external tailings storage areas $(\$ 100$ 'sM).

2. Excavate and process the ore body, using the external storage for tailings.

3. Use overburden and/or tailings sand for in-pit dyke construction (\$100'sM).

4. Transfer tailings from previous ponds to the new pond, once the previous facilities are nearly full of solids and the new dykes are complete.

5. Continue excavation and ore processing.

6. Return to (3) above and cycle until mining is completed.

This sequence results in hundreds of millions of dollars spent on constructing large earthen dyke structures suitable for storage of fluid deposits, then rapidly filling these structures with consolidating solids. We are left in an expensive cycle where construction of the water retaining structures is a continuous operation with each newly constructed pond subsequently filled with solids in short order. Other than the benefits obtained by construction and design groups, this investment in highly specialised dyke structures (included in the list of largest in the world) represents some of the highest costs and operational risks for the industry. There had to be a better way.

In order to determine what other options may exist, research efforts shifted to addressing the perceived primary challenge of accumulation of a type of fluid tailings known as mature fine tailings (MFT) described 
in previous works (Fine Tailings Fundamentals Consortium, 1995). A more directed treatment of this material could allow for greater flexibility in the use and placement of coarse sand and the separation of tailings treatment from bitumen production. This would allow extraction operations to focus on maximising bitumen recovery and avoid potential operational conflicts between maintaining reliable bitumen supplies and meeting tailings performance requirements. One example of these techniques which has been adopted (or is under field trials) by a number of oil sands operations is known as MFT drying (Wells and Riley, 2007) and this method is used as a basis for comparison in this discussion. The treatment methods involving the separation of the fine and coarse streams are presented here as segregated tailings treatment.

Once an alternative technology was identified, it became important to analyse the potential impacts of the integration of the new technology on the mining plan. The standard method of evaluating such potential impacts involves the assembly of performance parameters for the various technologies and, using the basic ore body characteristics, running a mining and tailings plan out to the end of mine life to compare the results to the base plan. This paper performs a similar analysis, albeit greatly simplified, in order to highlight some of the basic changes in tailings performance when examining the use of segregated tailings treatments as compared to standard historical tailings techniques.

\subsection{Assumptions and scenario definition}

Three scenarios will be discussed, each one using differing technologies to treat a single unit weight of ore. Table 1 shows the assumed sand ( $>44$ microns) and fines ( $<44$ microns) contents of the unit weight of ore, while Table 2 provides the parameters used in calculating the resultant deposit characteristics. The ore is represented as ratios of a unit weight of ore solids, and is generally representative of a good processing ore. Bitumen and water contents are ignored. All fines capture values are based on common Suncor planning parameters, and the beach densities are within commonly found field ranges. These values are applied to similar deposits in all the scenarios presented.

In terms of deposit types, Table 2 refers to beach above water (BAW), beach below water (BBW), consolidated tailings deposits (CT), mature fine tailings (MFT), and mature fine tailings dried (MFTD). These unit weight densities represent final dry solids densities post consolidation. The consolidated tailings parameters are interchangeably referred to as both CT and non-segregating tailings (NST).

Table 1 Ore solids properties

\begin{tabular}{lc}
\hline Unit Weight of Ore Solids Properties \\
\hline Sand (unit weight) & 0.88 \\
Fines (unit weight) & 0.12 \\
\hline
\end{tabular}

Table 2 Tailings deposit dry density parameters

\begin{tabular}{ll}
\hline Material Type & Unit wt/vol \\
\hline BAW & 1.576 \\
BBW & 1.49 \\
CT & 1.655 \\
MFT & 0.368 \\
MFTD & 1.576 \\
\hline
\end{tabular}

\subsubsection{Sub-aqueous beaching scenarios}

This scenario is reflective of the original oil sands operations, with unprocessed tailings streams discharged into holding ponds. Coarse sand rapidly settles to the bottom as a saturated beach, entraining a percentage of the fines. While a small percentage of the sand ends up as BAW, the vast majority is placed below the pond's waterline and is known as BBW. The remaining fines not captured in the beaches remain suspended 
in the overlying watercap, settling slowly over time. Once these fines reach a density of around $30 \%$ solids by weight (sbw), settlement rates are drastically reduced and the material is referred to as MFT.

Two of the examined scenarios refer to this basic methodology. The sub-aqueous beaching scenario is the base case, and does not involve any treatment of either the coarse or fines fractions. The sub-aqueous beaching with MFT drying scenario is the same coarse treatment, with the resultant fines in MFT dried in thin lifts.

For this discussion, the discharged tailings stream is assumed to have an average density of $50 \%$ sbw at the point of discharge into the pond. Coarse sand beaches form just off the deposition point and dewater rapidly to $76 \%$ sbw. The fines released to the water column are assumed to reach $30 \%$ sbw immediately, and while this immediate consolidation for the MFT is not strictly correct, under steady-state operating pond conditions it is a reasonable approximation.

In terms of quantifying the beach behaviours, $10 \%$ of the coarse sand ends up as BAW with $7 \%$ fines in the total solids and a $15 \%$ degree of saturation (percent of the deposit's void spaces containing water). The remaining sand forms BBW with $10 \%$ fines and under fully saturated conditions. In either case all coarse sand is stored within the pond area and hence behind constructed dykes.

MFT drying parameters are discussed in the segregated stream scenario, Section 1.1.3.

\subsubsection{NST scenario}

Tailings operations at oil sands over the last decade have been dominated by the use techniques similar to those laid out in this scenario. Coarse sand slurries from the underflow of hydro cyclones is mixed with MFT and a coagulant, most often gypsum, to form a NST known as consolidated (or composite) tailings as described in previous articles (Donahue et al., 2008). This material is highly resistant to shear, and can be pumped very long distances with centrifugal pumps under turbulent conditions without impacting the quality of the NST. This allows for the tailings treatment facilities to be located close to the extraction plants and hence within close proximity to the other major facilities such as power and water supplies.

Once the material is transported to the ponds, the major limitation on discharge is that the stream cannot flow through water columns, causing segregation of the MFT and sand. Discharges are done through submerged tremie lines or by beaching into high density ponds with no surface water (Wells, 2004). Surface fluids in the pond, including process water and MFT, are removed during operation in order to keep the overall pond level static. Once the CT deposit has displaced the fluid materials, tailings deposition stops and the CT is allowed to consolidate through self weight. By design, this consolidation process will take approximately 5-10 years, at which point the CT has sufficient strength to cap with sand and begin placing a reclamation surface.

The NST Scenario is based on Suncor's CT technology. This specific case assumes that production of the CT is sufficient only to consume the fines not captured in the beaches, and so only $26 \%$ of the total available sand is used for CT production. The remaining coarse sand is deposited into a pond under the same conditions as the Sub-Aqueous Beaching Scenario. This is representative of the overall sand supply across the complete lifecycle of an operation.

The NST or CT material is discharged with a stream average density of $60 \%$ sbw, an assumed sand-to-fines ratio (SFR) of 4:1, and is deposited sub-aqueously. While it is known that dynamic segregation of this CT material resulting in volumes of low SFR CT with much longer consolidation times occurs, this effect is ignored in this scenario and 'perfect' CT deposition is assumed. The final CT/NST deposit densities are based on common Suncor field values.

\subsubsection{Segregated stream scenarios}

These scenarios represent some of the most recent technology developments at oil sands. The first scenario, titled sub-aerial beaching, alone involves whole tails produced by extraction and pumped to a beach storage area. Discharge of the regular tailings occurs sub-aerially with the sand forming BAW deposits with the capacity to dewater through self-drainage. Excess fines not captured in these beaches are transported along with the drainage water to a settling pond for permanent storage. 
The second scenario, sub-aerial beaching and MFT drying, is similar to the previous scenario only as MFT accumulates in the settling pond, it is pumped out, mixed with gypsum and hydrated lime, and dried in thin lifts on slopes with a 1-4\% slope (Wells and Riley, 2007). Sufficient amounts of material are subjected to this MFT drying in order to maintain a zero MFT inventory.

The final variant, called sub-aqueous beaching and MFT drying scenario includes the same MFT drying operation only with the beaches deposited under a watercap into a traditional tailings pond area rather than self-draining beaches.

In the calculations for each scenario, sub-aerial beaches are assumed to be equivalent to BAW with a $15 \%$ degree of saturation. While the saturation levels are highly dependent on the design of the dewatering beach, the final analysis is relatively insensitive to this value and only affects the differential water recovery levels not the overall trend.

The fines which are not captured in the coarse deposit create MFT at $30 \%$ sbw. All the water contained in the source MFT is assumed lost to evaporation as part of the MFT drying process.

\section{$2 \quad$ Analysis criteria}

Tailings storage can be classified into two broad categories: sub-aqueous storage (ponds with dykes) and sub-aerial storage (piles with berms and/or dewatering systems). Each category has general geotechnical requirements and its own inherent performance considerations and requirements. In general, sub-aerial storage is accepted here as less risky than sub-aqueous storage.

When comparing the performance of various tailings options, several criteria are examined. Ultimately all options in a full evaluation effort are broken down to a cost profile, but this comparison is by necessity site specific and varies with the operating resources of the individual corporation. The discussion here will focus on basic technical parameters that form the primary controls on both the performance of the technology and the ultimate costs.

The key components for this evaluation of tailings performance include the water retained in the final deposit and the deposit's material storage requirements.

There are several other key contributors including environmental impacts, availability of additive chemicals, and availability of construction material. For simplicity, these are assumed to be equivalent in all the examined options and are therefore ignored. In cases where specific chemicals and/or long term landform drainage effects on the landscape differ from accepted or approved norms, these effects must be included in any full evaluation.

\section{Analysis results}

Figure 1 provides the results of the model run. 


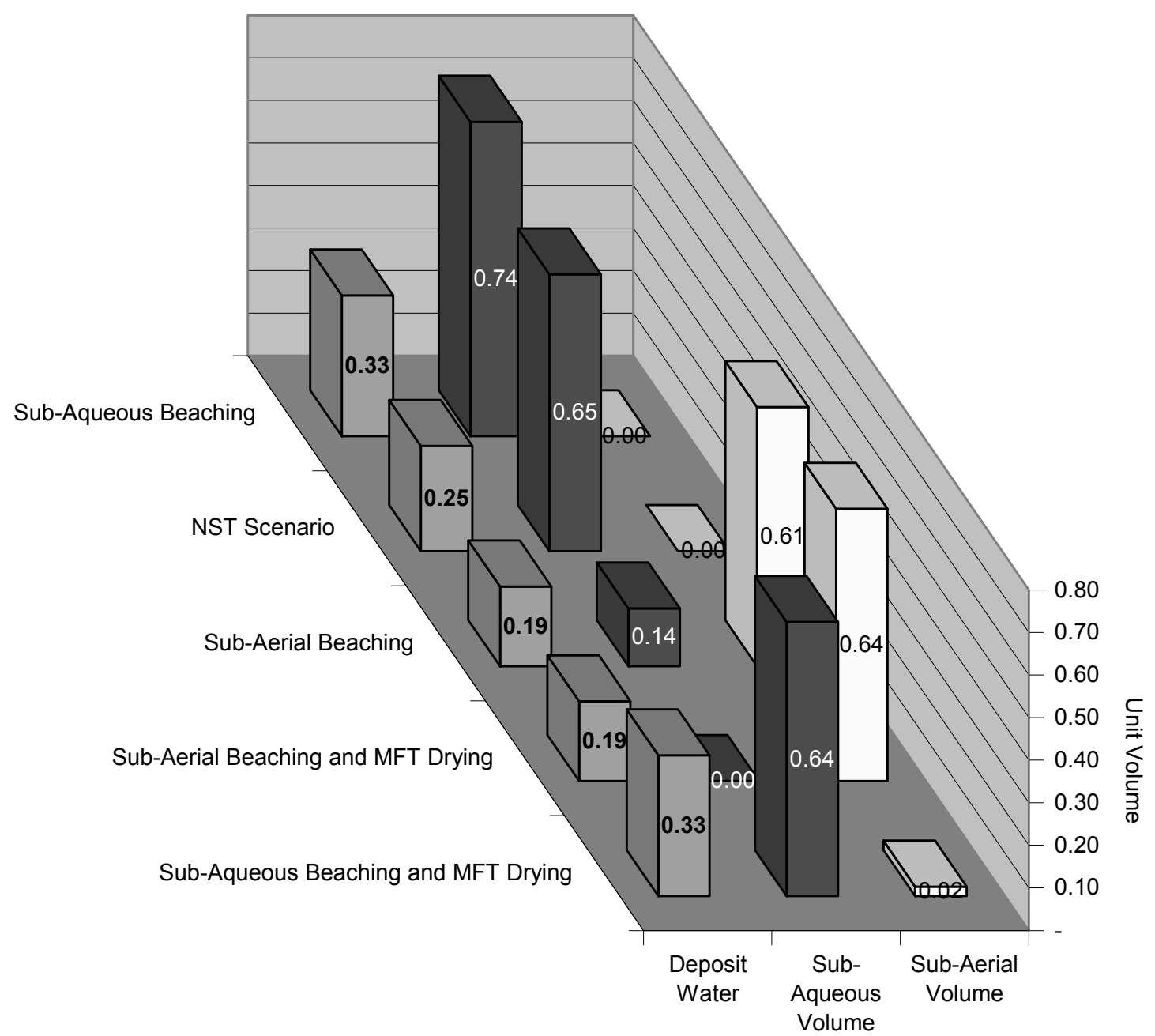

Figure 1 Fully consolidated tailings deposit unit volume by scenario

In this figure:

- deposit water is the volume of process water remaining in the tailings deposit after consolidation is complete

- sub-aqueous volume is the total volume of post consolidation material requiring storage within constructed ponds

- sub-aerial volume is the total volume of material placed in drying or self dewatering sub-aerial beaches, or in any case areas not behind substantial dyke structures.

Several observations are readily apparent from this chart.

First, the deposition of untreated whole tailings into a pond (sub-aqueous beaching option) results in the largest volume of water retained within the tailings deposits and the largest volume of sub-aqueous storage.

Second, the NST scenario improves on both the deposit water volumes as well as the overall pond storage volume when compared to the sub-aqueous beaching option.

Third, sub-aerial beaching improves on both deposit water and sub-aqueous volumes with the only material stored within a pond being the MFT. If this MFT volume is subjected to MFT drying as in the sub-aerial beaching and MFT drying scenario, no fluid storage is required at the end of mine life and all deposits are terrestrial in nature.

In the final option, sub-aqueous beaching and MFT drying, the deposit water volume is similar to the subaqueous beaching scenario, with the sub-aqueous volume essentially equivalent to the NST scenario. 
It is readily apparent that the largest benefit is gained in placing the sand in self-draining deposits, with additional marginal gains derived from drying the MFT. It is also readily apparent that the NST Scenario option is preferred only when compared to the two sub-aqueous beaching options.

\subsection{Consolidation times}

Consolidation times are critical when discussing the time to reclamation of tailings areas. This affects the time required between final deposition and reclamation, the type of reclamation landforms that can be achieved within the timeframe, the rates of water release during consolidation, and the suitability of the tailings areas for the various landform options. Ultimately the shorter the consolidation times the better. In the cases of the presented scenarios, we can compare the total volumes of materials produced with their required consolidation times represented by their permeabilities. In a keynote paper at the OSTRF conference (Sobkowicz and Morgenstern, 2009) a discussion on various tailings types and their characteristics as a function of sand, fines, and water contents was presented. When viewed on a ternary diagram based on this paper, shown in Figure 2, several conclusions can be made:

1. $\mathrm{BAW}$ and $\mathrm{BBW}$ rarely produce materials with $\mathrm{K}$ values less than $10^{-4} \mathrm{~cm} / \mathrm{s}$.

2. High SFR CT reach $\mathrm{K}$ values as low as $10^{-6} \mathrm{~cm} / \mathrm{s}$ before achieving final consolidation.

3. MFT will get up to two orders of magnitude less permeable $\left(\mathrm{K}<10^{-8} \mathrm{~cm} / \mathrm{s}\right)$ before reaching final consolidation limits when compared to CT.

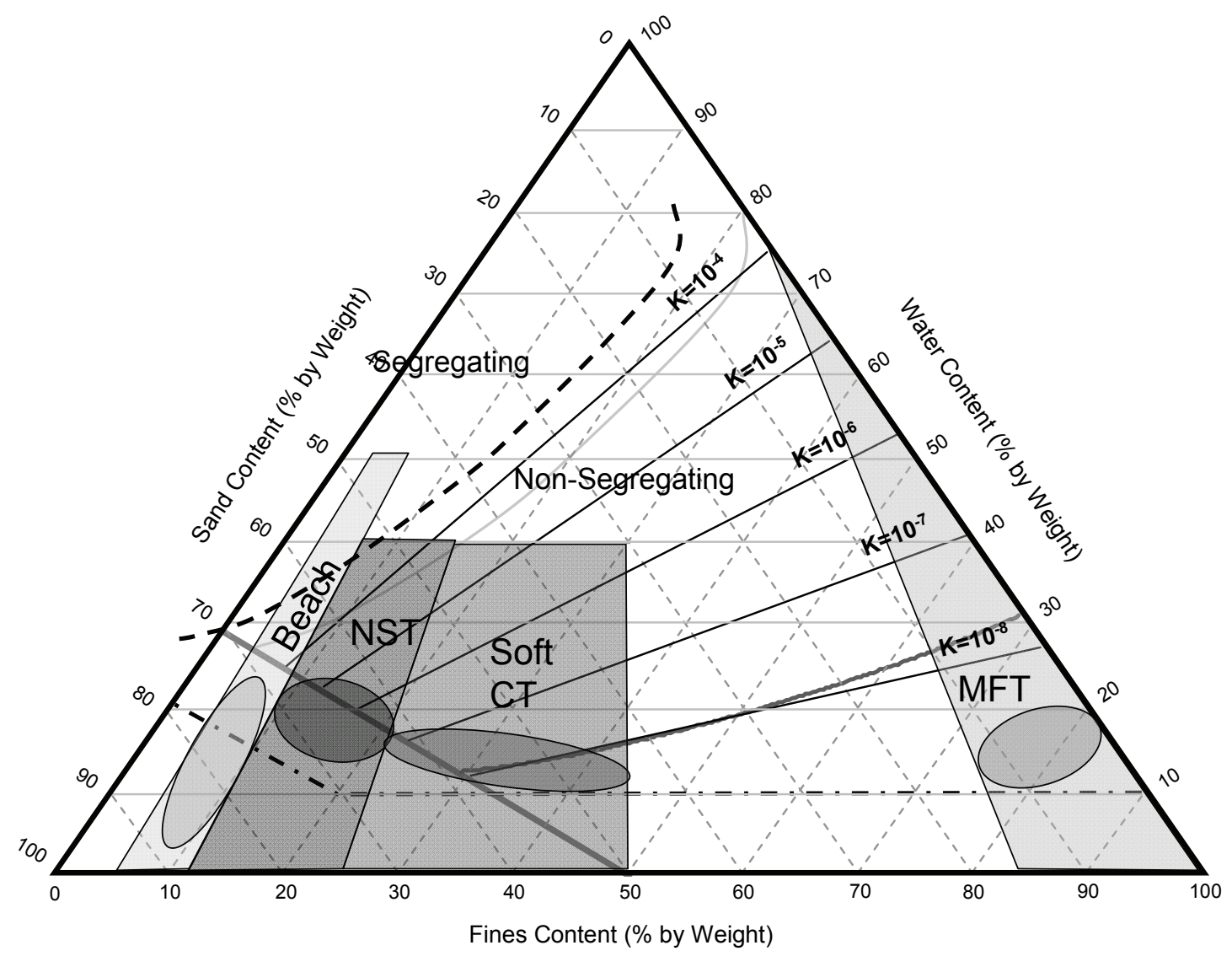

Figure 2 Tailings material consolidation path ternary diagram

In Figure 2, the top of each shaded section represents the density and solids makeup of the material as it enters the pond or other storage area. The ovals represent the final target densities. It should be noted that while beach, MFT and NST are discussed in this article, 'soft' CT is only presented to highlight one of the potential unplanned products of CT/NST production. It is a term used by some in the oil sands industry to define CT materials with low sand-to-fines ratios, and is not related to the strict geotechnical definition of 
'soft'. This material is the result of either the partial dynamic segregation of CT during deposition or inadequate process control during production resulting in lower sand contents than planned. It is very important to recognise that, based on the segregation boundary shown, Soft CT is a more robust mixture and thus easier to produce and deposit as a non-segregating stream in a pond when compared with proper CT/NST. While this is a major operational concern, it is not included in the evaluation of the scenarios presented here.

Conceptually it appears that mixing the very low permeability MFT with sand in order to produce CT/NST should result in improved tailings plans and deposit behaviours. However, some key material balance planning parameters are left out in this simple analysis:

- comparative volumes of the MFT dried and the NST produced

- thickness of these volumes once deposited in appropriate storage (thin lifts versus ponds)

- timeframes for onset and completion of consolidation of these volumes.

This total tonnes of material that goes to MFT drying is approximately $1 / 5$ th the total material that would go to NST deposits. In addition, under the MFT drying scenarios, each lift of MFT is completely consolidated before the next lift is placed resulting in some fully consolidated deposits almost as soon as drying operations begin. In contrast, much of the consolidation of the NST deposits cannot begin until after deposition is completed. A pond may take 5-10 years to fill producing deposits as deep as $75-100 \mathrm{~m}$, meaning that the CT deposit will not reach a capable state until 5-10 years after production is completed, and reclamation may be limited at that time by the strengths of the underlying consolidated tailings. The thin lift MFT drying allows for a longer timeframe to deal with the consolidation of the material, and while drying may require a significant surface area, it must only continue long enough to consume the last of the fines in MFT storage once mining is completed. In the worst case scenario, this would mean final deposition of the fines inventory within 2-3 years after mining is complete and would result in the achievement of fully consolidated landscapes suitable for any reclamation landscape. In the timeframes currently proposed by regulators, NST deposits may result in limited practical options for the final landform designs. These options may consist of those suitable to low geotechnical strengths, with the exact strengths uncertain until final closure and reclamation efforts begin.

\subsection{Tailings volumes and contained water}

The development and acceptance of NST and CT has been predicated on three basic assumptions:

1. Total storage volume with a CT process is less than for regular tailings.

2. Water volumes for recycle are increased with a corresponding reduction in water lost to tailings deposits.

3. CT deposits provide increased fines capture in rapidly consolidating materials.

When compared to the base sub-aqueous beaching scenario, this is mostly correct. The use of NST to consume the MFT inventories provides an operational storage reduction of around $10 \%$ and an ultimate fluid storage reduction of $11.5 \%$. This is coupled with an ultimate reduction of water lost to tailings of $25 \%$ over sub-aqueous beaching operations.

In the case of the segregated stream sub-aerial beaching and MFT drying scenario, the initial operational volume of tailings is approximately equivalent to the sub-aqueous beaching plan with the exception that most of the stored tailings are placed outside of fluid storage areas. Once final consolidation and MFT drying treatments are done, the total storage volume is $13 \%$ less than the sub-aqueous plan, and $2 \%$ less than the NST plan. When discussing the water contained in tailings deposits, the NST plan has $25 \%$ less water than the sub-aqueous plan, while the segregated stream plan has $43 \%$ less than the sub-aqueous beaching scenario and $24 \%$ less than the NST scenario.

In is readily apparent that even with the earlier MFT drying technology examined here, it is difficult for NST-based solutions involving saturated depositions to complete with even the most basic option involving the sub-aerial beaching of coarse tailings. Advances in technology for MFT drying are now indicating that $50 \%$ or more of the total water contained within the source MFT can be liberated as free water and reused or 
treated. If applied to this analysis, the improved process would increase the total efficiency and water recovery of any of the segregated stream plan and can prove capable of treating legacy volumes without unreasonable increases in land use for tailings.

\section{$4 \quad$ Recommendations}

Segregated tailings treatments appear to be a preferred option.

This analysis indicates that deposition of the coarse fraction of the tailings materials should be as free draining structures, which reduces the operational risk of containing large volumes of saturated materials, reduces the total amount of water lost to deposits $25-40 \%$ over the life of the operation, and also permits the rapid reuse of process water. Fines streams should be treated separately, preferably through thin or thick lift deposition, to minimise the total operational storage of fluids through the rapid dewatering of these streams. While treating volumes of legacy fines materials which may require large surface areas for effective operations, the advantages gained from segregated tailings treatments should not be overlooked. Green fields operations should be able to keep fluid inventories at a static minimum with less overall surface disturbance than has been achieved historically, with increased options for final reclamation within shorter timeframes than is achievable with NST.

While the sub-aerial beaching of tailings sand is not a trivial exercise, the processes are well known and several precedents have been set. MiBRAG in West Germany and Syncrude in the Oil Sands have successfully built significant volumes of sub-aerial sand deposits using a variety of methods, and the techniques are well known.

MFT Drying as a purely evaporative process represents the most conservative method available. Advances since the 2007 paper have resulted in techniques with minimal reliance on evaporation, allowing for up to $85 \%$ of the water from the MFT to be recovered for use. Further advances in polymer treatment will continue to improve the techniques, reducing the time to final consolidation and increasing the percentage of water recovery.

\section{Conclusions}

No technology is applicable in all situations and must be evaluated for use in any specific operation or planning option. In the arguments presented here, general assumptions have been made that may or may not apply. In general, the utilisation of segregated stream tailings treatment can be said to be preferred over NST systems, based primarily on the assumption that NST materials must be deposited within ponds as saturated deposits. Options that may allow for sub-aerial NST deposition may change these conclusions, but must overcome the volume discrepancies between treating just the fines and treating the fines plus the required volumes of coarse material.

Several technical and mine planning exercises have been undertaken at Suncor's operations, and they have consistently pointed towards segregated tailings treatment options for many of the reasons discussed here. While this is not likely a universal truth, it is an evaluation worth considering.

\section{References}

Donahue, R., Jeeravipoolvarn, S., Scott, D. and Ozum, B. (2008) Properties of Non-segregating Tailings Produced from the Aurora Oil Sands Mine Tailings, in Proceedings First International Oil Sands Tailings Conference, OSTRF/CONRAD, Edmonton, AB, pp. 143-152.

Fine Tailings Fundamentals Consortium (1995) Vol I. Fundamental Properties of Fine Tails in: Advanced in Oil Sands Tailings Research, Alberta Department of Energy, Oil Sands and Research Division, pp. 45-54.

Sobkowicz, J. and Morgenstern, N.R. (2009) A geotechnical perspective on oil sands tailings, in Proceedings Tailings and Mine Waste '09, U of A Geotechnical Centre, Edmonton, AB, pp. xvii-xli.

Wells, P.S. (2004) Advances in CT Deposition at Suncor Energy, Oilsands, CONRAD Tailings Seminar, Edmonton, Powerpoint presentation.

Wells, P.S. and Riley, D.A. (2007) MFT Drying - Case Study in the Use of Rheological Modification and Dewatering of Fine Tailings Through Thin Lift Deposition in the Oil Sands of Alberta, in Proceedings Tenth International Seminar on Paste and Thickened Tailings, A.B. Fourie and R.J. Jewell (eds), Australian Centre for Geomechanics, Perth, Australia, pp. 271-284. 